\title{
LA GRIPE ESPAÑOLA DE 1918 A TRAVÉS DE LA OBRA DE LAURA SPINNEY EL JINETE PÁLIDO
}

\section{The 1918 Flu Pandemic through Laura Spinney's book "Pale Rider"}

\author{
María SAMPEDRO PUERMA; Guillermo SÁNCHEZ CAMPELO \\ Facultad de Medicina y Ciencias de la Salud. Universidad de Oviedo (España). \\ Correo electrónico: mariasampedropuerma@gmail.com; guillermosanchezcampelo@gmail.com
}

Fecha de recepción: 11 de septiembre de 2020

Fecha de aceptación: 15 de septiembre de 2020

Fecha de publicación: 29 de enero de 2021

\begin{abstract}
Resumen
De entre todas las pandemias, la gripe española de 1918 es, sin duda, la más mortífera y destructiva en términos absolutos que haya sufrido la especie humana, llegando algunas estimaciones a los 100 millones de muertes. Provocada por el virus de la gripe A subtipo H1N1, se desarrolló en el contexto de la I Guerra Mundial, un hecho totalmente novedoso en la presentación de una enfermedad. Sus repercusiones se entremezclan y difuminan con las de un conflicto que asoló buena parte del viejo continente, agravando así sus consecuencias. Sin embargo, esta pandemia hizo evidente la necesidad de un sistema de salud pública eficaz, de modo que la mayoría de los países del mundo tomó medidas en este aspecto. Cien años después, la ciencia y la medicina se han visto desbordadas en la pandemia de COVID-19, combatiéndola con armas muy similares a las ya vistas contra la gripe española. iOjalá hayamos aprendido la lección!
\end{abstract}

Palabras clave: gripe española de 1918; pandemia; arte; literatura.

\section{Abstract}

Among every pandemic, the Spanish flu of 1918 was without any doubt the deadliest in absolute terms, with some estimations reaching the amount of 100 million deaths. It is caused by the influenza A virus subtype H1N1 and it developed during the first World War, something never 
seen before in the appearance of a disease. Its repercussions jumbled with the armed conflict, making its consequences even worse. However, this pandemic made it obvious that a public health system was needed. During the following years, most of the countries all over the world took action in this regard. 100 years later, science and medicine have been overtaken by the COVID-19 pandemic, fighting against it with tools and weapons also used against the spanish flu. We hope to learn the lesson this time.

Keywords: spanish flu; pandemic; art; literature.

"Es posible procurarse una seguridad frente a las demás cosas, pero, frente a la muerte, todos los seres humanos habitamos una ciudad sin murallas" (Epicuro, siglo III a. C).

\section{INTRODUCCIÓN}

Si, hace unos meses, se pregunta a nuestros contemporáneos cuáles han sido los acontecimientos más dantescos que perduran en sus memorias acerca de los siglos pasado y presente, la mayoría de ellos harían alusión a las grandes guerras y todo lo que conllevan. También se hablaría por ejemplo de la llegada del hombre a la Luna, de la caída del Muro de Berlín o de la desaparición de los grandes imperios y la independencia de los países africanos y muchos asiáticos. Hoy en día, la respuesta sería probablemente muy distinta. En ello, influiría sin lugar a duda, que el SARS-CoV-2 forma parte de nuestro equipaje, y además se caracteriza funestamente, por su óptima capacidad para camuflarse y viajar por un mundo en el que la globalización es su seña de identidad.

Las pandemias, desde el inicio de los tiempos, acechan a la humanidad y son una de las mayores amenazas de nuestro mundo junto al cambio climático. Han eclipsado imperios, diezmado ejércitos, provocado hambrunas, arruinado ciudades y puesto fin a guerras o comenzado otras. También han tenido como consecuencias cambios en la forma de ver el mundo en todos los ámbitos y abordar los problemas, ya sean cotidianos o complejos. Pero, sobre todo, hay algo muy importante que tienen en común todas ellas: han provocado mucho sufrimiento. Hasta la llegada de la COVID-19, las cinco pandemias más letales han sido, por el orden que sigue, la viruela, el sarampión, la gripe de 1918 , la peste negra y el $\mathrm{VIH}^{1}$.

Echando la vista atrás, reconoceremos las pandemias como un hito histórico de mayor o menor relevancia en función de sus consecuencias y repercusiones. Muy probablemente las primeras epidemias surgieron ligadas al auge de las ciudades, lugares más que propicios para la propagación de una enfermedad, en las que el hacinamiento y la falta de higiene fueron claves para su expansión entre la población humana. Como en muchos otros casos, no existe constancia escrita de la que se podría llamar la primera epidemia, pero ciudades como la mesopotámica Uruk, la mayor urbe de su tiempo con una elevadísima densidad de población de 80.000 habitantes en tan solo 6 kilómetros cuadrados amurallados, son un perfecto candidato para albergarla hace 5.000 años.

De las que sí hay constancia, podemos hablar de la epidemia que atacó la civilización griega durante la Guerra del Peloponeso: la plaga de Atenas entre 430 a. C y 425 a. C. Esta, como su nombre indica, afectó principalmente a la ciudad-estado de Atenas, pero también a otras partes del mundo griego y a otras regiones como Egipto o Etiopía². En el Imperio Romano destacan plagas como la peste antonina entre los años 165 y 180, o la peste cipriana que se produjo 60 años después. Ambas supusieron una pérdida de vidas importante $y$, sin duda, agravaron algo más el lento declive del imperio. Otro elemento muy relevante es la peste de 
Justiniano, acontecida entre los años 541 y 549, que frenó las aspiraciones del Imperio Bizantino a recuperar todo el esplendor del Imperio Romano, provocando una gran crisis económica y de pérdida de vidas. Sin duda, ya casi finalizada la Edad Media, la plaga más conocida es la famosa Peste Negra del siglo XIV, que asoló Europa reduciendo a menos de la mitad su población. Otra epidemia con consecuencias históricas importantes fue la viruela, trasladada a América por los conquistadores españoles en el siglo XVI, exterminando a buena parte de los habitantes indígenas que no estaban inmunizados contra ella. Probablemente sea una de las causas más importantes del éxito de los conquistadores, pero esta enfermedad siguió afectando durante mucho tiempo a las poblaciones humanas hasta darse recientemente por extinguida. Durante los siglos XVII, XVIII y XIX se produjeron otras tantas más, con algo menos de relevancia. Destaca la pandemia de gripe "rusa" a finales del XIX, a las puertas del siglo XX ${ }^{3,4}$. Entre 1918 y 1920, una pandemia de gripe se propagó desde EE. UU. al resto del mundo, matando a más personas en 24 semanas (un tercio de la población mundial) que el VIH en 24 años 5 .

Para concluir con este repaso histórico, más recientemente hemos visto otras cepas muy virulentas de gripe, como la gripe asiática o la gripe de Hong Kong. También, el temido SIDA, surgido en la década de los 80 del siglo pasado, o los diferentes brotes de ébola. Pero, por otra parte, los avances en la medicina y en la salud pública han permitido controlar de forma más eficaz otras amenazas surgidas recientemente, como la gripe A o el SARS-Cov-16,7. Así, hasta llegar a la pandemia de SARS-Cov-2 en este año 2020, cuyas consecuencias ahora mismo son totalmente inciertas.

Si se consigue que las pandemias nos inviten a reflexionar cuán frágiles somos si un microorganismo, a veces sin vida propia, es capaz de ocasionar, de facto, una hecatombe de tal magnitud que paraliza el mundo ${ }^{5}$, hemos logrado alcanzar conciencia colectiva. De este modo, seremos conscientes de que las enfermedades de masas son mayoritariamente zoonosis; es decir, han experimentado un proceso evolutivo pasando de ser enfermedades únicamente animales a convertirse también en humanas $y$, estaremos expectantes cada vez que surja una nueva cepa de la familia Influenza tipo $A$ o que un Coronavirus se transmita de los animales a los humanos ${ }^{8}$.

Las pandemias, grosso modo, son amplias en cuanto a espacio geográfico pero condensadas en el tiempo. Por ello, merecen ser descritas desde una perspectiva circular, que no lineal, al estilo en el que se presenta el texto judío "Talmud". En líneas generales, cualquier pandemia obliga a tomar decisiones extremas y precipitadas con enormes costes en base a escenarios probables. Sin embargo, existen dos factores decisivos que condicionan su resolución: las experiencias previas y el conocimiento acerca del agente causal de la amenaza.

La pandemia de gripe de 1918 en la que nos centraremos a posteriori, la mal llamada "gripe española", recibió tal denominación porque al estar medio mundo inmerso en la Primera Guerra Mundial, los contendientes no informaron sobre la enfermedad que estaba diezmando a sus soldados para no alentar a los adversarios. España daba a conocer los hechos reales acaecidos sin argucias, al mantenerse neutral en el conflicto bélico. Además, dicha pandemia fue llamada también "Soldado de Nápoles", al igual que la canción que por aquel entonces sonaba reiteradamente en una zarzuela9 . La decisión fue tomada por la similitud de la contagiosidad de la enfermedad y de dicha canción. También la expresión "mal de moda" hace alusión a la misma.

A diferencia de la gripe estacional, la población diana no eran solamente niños y ancianos, sino también adultos de mediana edad. La falta de desarrollo de la medicina y de un sistema de 


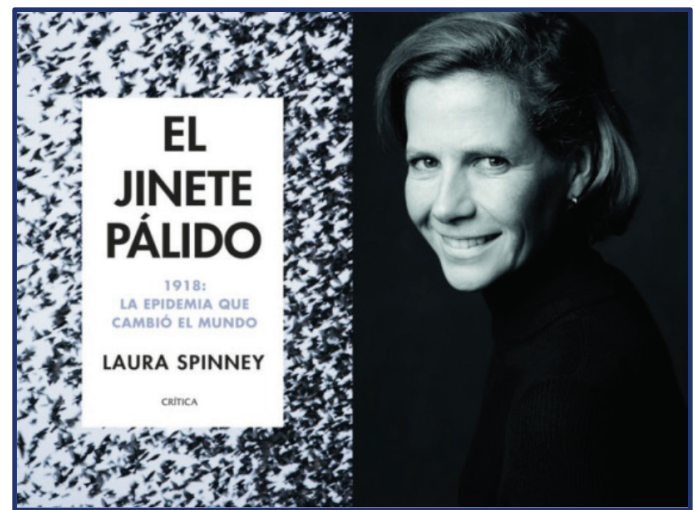

Figura 1. Portada del libro El jinete pálido en su versión en castellano junto a una fotografía de su autora, Laura Spinney. Tomada de Spinney L.

El mayor desastre del siglo XX. El Periódico, 5 de febrero de 2018.

salud pública eficaz, provocó que el problema se hubiera agravado aún más. A pesar de poner en marcha medidas para contener la epidemia, el sistema sanitario quedó sobrepasado. Los médicos no abundaban, llegando a tener que reclutar voluntarios entre los estudiantes de medicina. Además, en algunas ciudades españolas hubo que solicitar cooperación al ejército, para transportar y dar entierro a los fallecidos ${ }^{9}$. Las repercusiones de este desastre influyeron en la literatura y en el arte. Tal vez, ha sido responsable del interés desmesurado de artistas del siglo XX en mostrar la debilidad del cuerpo humano como elemento susceptible de ser abatido por la enfermedad. Así mismo, el "Soldado de Nápoles" llevó a la tumba a importantes figuras de la época de todos los ámbitos.

El objetivo del presente artículo es realizar una aproximación a la denominada "Gripe española" mediante la obra de Laura Spinney que lleva por título El jinete pálido ${ }^{10}$. Haremos una breve semblanza de la autora y comentaremos el origen y difusión de la epidemia, las características del agente causal y algunas características de la propia enfermedad, tales como antecedentes de los pacientes, cómo se manifiesta, el cuadro clínico más frecuente, la severidad, la toma de contacto de los pacientes con los sistemas de salud de la época, el tratamiento y la repercusión social de la enfermedad.

\section{SEMBLANZA DE LA AUTORA}

A modo de semblanza de Laura Spinney podemos decir que es periodista científica y novelista británica. Se graduó en Ciencias Naturales por la Universidad de Durham. A lo largo de su carrera profesional ha escrito para prestigiosas revistas y periódicos como Nature, National Geographic, New Scientist, The Guardian, etc. Algunos de los libros más conocidos de la autora son: The Doctor, The Quick, Rue Centrale y Derborence: Where the devils came down. La autora sigue con preocupación la situación actual como demuestra la entrevista concedida al diario $A B C$ en la sección de Ciencia el pasado 30 de abril de 2020, en la que la autora afirma: "La pandemia es una advertencia sobre los peligros reales que afronta la humanidad" y "Es muy probable que la próxima pandemia sea provocada por algún tipo de gripe ${ }^{11 "}$.

\section{RESULTADOS}

\section{Origen y difusión}

En el año 2020, se puede afirmar con certeza que la gripe española no empezó en España, de tal modo, que continúan en juego tres posibles orígenes: Kansas, Francia y China, aunque la opinión más extendida es que la gran difusión mundial tuvo como epicentro el estado de Kansas a través de los soldados que se incorporaban a la I Guerra Mundial. Además, esta pandemia recorrió el mundo con mayor celeridad, en comparación con las sufridas anteriormente. Éstas, solían tardar tres años en recorrer el planeta, sin embargo, el "Soldado de Nápoles" lo hizo en tan solo dos años, de 1918 a 1920. Entre tanto, conviene señalar que, para llevar a cabo dicho 
cometido, éste hizo notar su protagonismo a nivel mundial en tres ocasiones -algunos han sugerido que hubo una cuarta- conocidas popularmente como "oleadas de la gripe española". La presentación de estas fue muy desigual, confundiéndose la primera con una gripe estacional y la segunda con la peste neumónica, mientras que la tercera poseía una virulencia intermedia. Al hilo de lo anterior, se debe resaltar que la mayoría de las muertes se produjeron en solamente trece semanas, desde septiembre hasta mediados de diciembre de 1918.

\section{Agente causal}

Atrás quedó un arduo camino hasta llegar a la identificación del agente etiológico, virus Haemophilus Influenzae, subtipo H1N1. En principio, se pensaba que dicho microorganismo, también llamado "bacilo de Pfeiffer", a quien debe su denominación, era una bacteria con diferentes cepas. No obstante, ya en 1916, Milton Rosenau sospechó que el agente etiológico pudiera ser un virus. Éste, debido a su ínfimo tamaño, estaba capacitado para atravesar los poros de los filtros de porcelana de Chamberland, utilizados en aquella época para atrapar las bacterias de un líquido, recibiendo así el apelativo de "virus filtrable". En 1918, los científicos Dujarric y Lacassagne decidieron realizar un experimento para corroborar la hipótesis. Para ello, este último inyectó al propio Dujarric sangre filtrada de un paciente con gripe, desencadenándose un cuadro gripal a los dos días de la inoculación. Posteriormente, en un segundo experimento realizado, tomó una emulsión filtrada de esputo de pacientes enfermos y la aplicó en su garganta. Llegó entonces a la conclusión de que la ausencia de síntomas era debida a la adquisición de inmunidad promovida por el primer experimento. De otro modo, los científicos pasteurianos Nicolle y Lebailly, llegaron a la conclusión de que el causante de la enfermedad era un virus que además no se

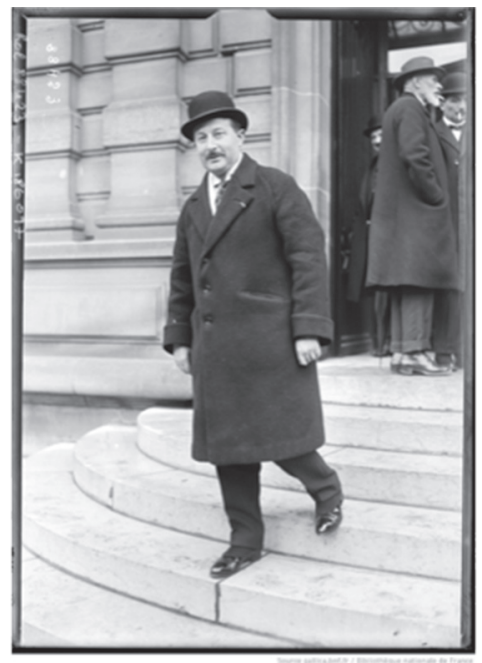

Figura 2. Fotografía de René Dujarric de La Rivière a la salida del Instituto Pasteur. Extraído de Gallica- Bibliothèque Nationale de France. Accesible en: https://gallica.bnf.fr/ark:/12148 /btv1b531210064.item

podía transmitir por vía sanguínea. Así fue como los tres publicaron, en distintos trabajos, pero de manera simultánea, que probablemente la gripe de 1918 estuviera causada por un virus.

Hoy es de sobra conocido, que el signo más revelador de que una especie concreta es reservorio de un determinado patógeno es que no enferme del mismo, debido a la coevolución de virus y huésped. Así es como se considera a las aves, en especial las acuáticas, reservorio natural de la gripe. Con la llegada de la revolución agrícola, sobrevino la domesticación de algunas aves y consecuentemente, el paso a convivir en las aldeas con los humanos. Además, se cree que los cerdos jugaron un papel de suma importancia como intermediarios, ya que sus células comparten características con las de aves y humanos.

En relación con el mecanismo de transmisión puede afirmarse que es la vía aérea, en contraposición a las creencias obsoletas y atávicas de que el aire nocivo o "miasma" (término acuñado en 
época galénica) que emanaba de los cadáveres en los campos de batalla, era el desencadenante de la transmisión de la enfermedad. A pesar de que la "teoría de los gérmenes" existía desde hacía medio siglo y la población era capaz de comprender el término "contagio", aún pululaban sombras inciertas en relación con el mecanismo de propagación.

Un siglo después de la pandemia y tras visionarse por vez primera el virus en 1943, se puede afirmar que es de tamaño mediano, con morfología casi esférica y está envuelto por una membrana que contiene hemaglutinina $(\mathrm{H})$ y neuraminidasa $(\mathrm{N})$ como antígenos. Además, desde el punto de vista genético, contiene RNA monocatenario empaquetado en ocho segmentos, de los cuales dos de ellos se traducen en proteínas de superficie ( $\mathrm{H}$ y N) y los otros seis codifican proteínas responsables de la patogenicidad, como pueden ser la capacidad del virus para replicarse o el rechazo de la respuesta inmunológica del huésped. Cabe reseñar por ser realmente inquietante, que la inestabilidad bioquímica del RNA, en comparación con el DNA, está irrevocablemente

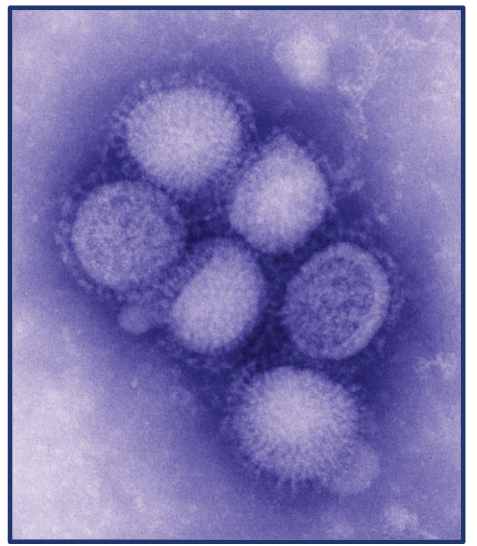

Figura 3. Imagen del influenzavirus $A$ H1N1 tomada en el Centro de Control de Enfermedades de Estados Unidos. Dominio Público, https://commons.wikimedia.org/wiki/ File:H1N1_influenza_virus.jpg relacionada con el acúmulo lento de errores que acaecen durante el proceso de replicación y que recibe el nombre de "deriva". Es esto último lo que confiere la inaudita capacidad mutante de la partícula viral.

En cuanto a las posibles variantes de gripe, de las cuatro conocidas a fecha actual (A, B, C y D) únicamente la variante $A$ es responsable de causar pandemias. También conviene señalar que existen hasta la fecha, dieciocho variantes conocidas de hemaglutinina y once de neuraminidasa.

Respecto al siglo XX resulta notorio que cada pandemia fue desencadenada por la aparición de un nuevo antígeno $\mathrm{H}$ en la gripe A: $\mathrm{H} 1$ en 1918, H2 en 1957 y H3 en 1968.

\section{Antecedentes personales del enfermo y población diana}

Es sabido con certeza que la existencia de una enfermedad subyacente incrementaba la vulnerabilidad a la gripe, si bien es cierto que, grosso modo, la población de 1918 estaba atemorizada y sorprendida por la aleatoriedad con que la enfermedad acechaba a las víctimas.

Además de ancianos y niños de corta edad, las personas jóvenes y robustas, de entre veinte y cuarenta años, principalmente varones, se encontraban en la línea de fuego. Una de las hipótesis que gira en torno a la causa de lo anterior, considera que los sistemas inmunes más potentes presentan una tormenta de citoquinas más agresiva.

La curva de mortalidad muestra una forma de $\mathrm{W}$ asimétrica, a diferencia de la forma de $\mathrm{U}$ habitual en el caso de la gripe estacional. Aún queda por dar explicación al hecho de situar a los jóvenes de quince años con un sistema inmune potente en la primera depresión de la W. También, igualmente se espera respuesta al por qué el trazo ascendente de la derecha estaba atenuado, lo que denota que los ancianos estaban más protegidos de lo habitual. 
En la mayoría de los países, las mujeres eran menos propensas a contraer la enfermedad salvo las embarazadas, las cuales estaban aquejadas también de abortos espontáneos y partos prematuros con asiduidad. Con relación a lo anteriormente expuesto, cabe reseñar a modo de distinción que, en la India, la letalidad a causa de la gripe española era mayor en las mujeres. Entre los factores facilitadores, se podrían citar una alimentación deficitaria, principalmente vegetariana, a lo que se adiciona el hecho de que fuesen las mujeres de la casa las encargadas del cuidado de los enfermos ya abatidos por la gripe.

Otro hecho llamativo era la desigualdad geográfica. Por un lado, las ciudades, debido a su densidad de población, se hallaban más afectadas que las zonas rurales. Por otro, también existían discrepancias a nivel continental, de tal manera que los que vivieran en determinadas zonas de Asia, tenían treinta veces más probabilidad de fallecer a causa de la gripe que si vivieran en ciertas partes del viejo continente.

Otros factores que quizás tuvieran que ver con la vulnerabilidad a padecer la enfermedad fueron el aislamiento geográfico, la falta de exposición histórica al virus, la cultura, el tipo de dieta... e incluso, su DNA. Como ejemplo de lo anterior, se podría resaltar el devastador impacto de la gripe española sobre los inmigrantes italianos que habitaban, por entonces, en Connecticut (EE. UU.). Parece ser que ello ha sido motivado por razones de desigualdad, tanto en el ámbito económico como en el jerárquico.

\section{Primeros síntomas}

La triada constituida por irritación de garganta, fiebre y dolor de cabeza fue considerada la afectación inicial. Albert Gitchell, cocinero del campamento Funston en Kansas, así lo manifestó en la enfermería aquella mañana del 4 de marzo de 1918. Tras él, el resto de los compañeros manifestarían la misma sintomatología en un breve periodo de tiempo. Al igual que en la gripe

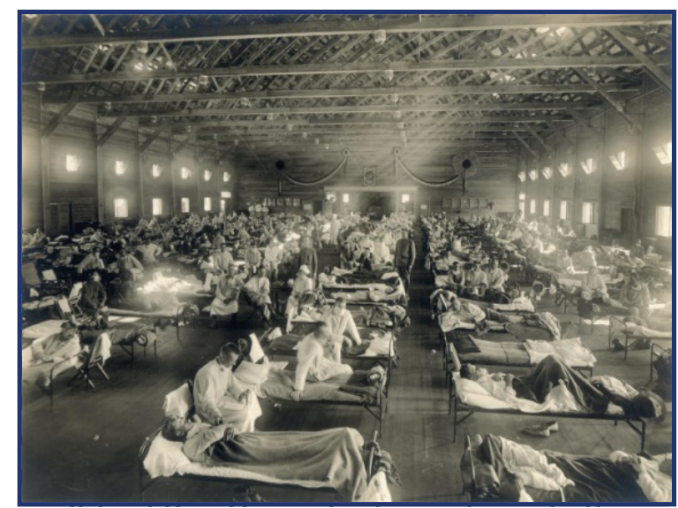

Figura 4. Fotografía del campamento Funston en Kansas, una de las posibles zonas de origen de la pandemia. Extraido de otis historical archives, national museum of health and medicine emergency hospital during influenza epidemic (ncp 1603), national museum of health and medicine. https://www

.buckscountycouriertimes.com/news/20190923

/mxfctter-museum-to-mark-historic -influenza-pandemic/1, dominio público, https://commons.wikimedia.org/w/index . php?curid $=25513204$

estacional, la mayoría de las personas que enfermaron en la primavera de 1918 se recuperaron, de forma semejante a lo ocurrido cada invierno ${ }^{12}$.

\section{Cuadro clínico}

Las manifestaciones clínicas o síntomas patognomónicos, además de los anteriormente reseñados como iniciales, son las siguientes: tos, mareos, vértigo, vómitos, disnea, visión borrosa, discromatopsia por inflamación del nervio óptico, pérdida de audición u olfato, caída de dientes y cabello, hematuria, hemorragias nasales y orales de manera espontánea, palidez, cianosis, insomnio, agitación, convulsiones y delirio, el cual paradójicamente, afloraba cuando la fiebre había remitido.

No existía manera de diagnosticarla con certeza al carecer de la oportunidad de tomar 
imágenes radiológicas o determinar parámetros analíticos. En general, el médico realizaba una anamnesis, medía la temperatura y llevaba a cabo una exploración física encaminada, entre otras cosas, a la búsqueda de las reveladoras manchas de color caoba en los pómulos. Si el clínico perseguía un diagnóstico certero, entonces tomaba una muestra de esputo $y$, tras cultivo en un gel nutritivo, lo observaba al microscopio.

\section{Gravedad}

En general, la segunda oleada de gripe fue la causante de los cuadros clínicos de mayor gravedad, llegando a ser letales en muchas ocasiones. Esta responsabilidad era atribuida la mayor parte de las veces a una neumonía bacteriana como complicación asociada. Cuando ésta aparecía, solía desencadenar el hoy conocido como SDRA (Síndrome de Dificultad Respiratoria Aguda) caracterizado por hipoxemia, taquipnea, hipotensión, taquicardia y cianosis.

La "cianosis" era un indicador de la gravedad. Con frecuencia, aparecían dos manchas de color caoba en los pómulos, que se extendían horas después hasta cubrir todo el rostro. En este sentido y de acuerdo con la descripción de un médico militar estadounidense, podía llegar a tal punto, que resultara difícil distinguir a una persona de raza blanca de una de color. Esta cianosis, conocida como "heliotrópica", determinaba en gran medida el pronóstico. Se podría ser optimista cuando la coloración tornaba a rojo, y pesimista cuando se mezclaba con el malva hasta alcanzar un tono negruzco que indicaba la máxima gravedad. Este color prieto, cuasi negro, se localizaba primeramente en las extremidades superiores e inferiores, incluyendo las uñas, e iba ascendiendo hasta alcanzar un tórax intensamente inflamado. La muerte llamaría al paciente en cuestión de días u horas.

En exámenes necrológicos practicados, los patólogos hallaban unos pulmones rojizos, inflamados y congestionados por la hemorragia. Estos estaban a su vez, recubiertos por una espuma rosácea acuosa. Era frecuente afirmar en la época por parte de los clínicos que las víctimas morían asfixiadas por sus propios fluidos.

El célebre médico ruso Bardakh, mentó que la variedad española de la gripe de 1918 se había caracterizado por ir acompañada de complicaciones nerviosas y respiratorias.

Desde el punto de vista psiquiátrico, los síntomas solían ser efímeros, si bien es cierto, algunos pacientes consumaron el suicidio por precipitación desde las ventanas de los hospitales, víctimas de la depresión. También se observó que un gran número de personas ya restablecidas de la gripe, ingresaron a posteriori en el Hospital Psicopático de Boston con un cuadro clínico consistente en la presencia de delirios y alucinaciones. Aun cuando a un tercio de estos se les diagnosticó dementia praecox (demencia precoz) como término análogo a la incurable esquizofrenia de nuestros tiempos, se hallaban en un error, pues cinco años más tarde la mayoría se habían recuperado por completo. Era entonces necesaria una nueva etiqueta diagnóstica para caracterizar a un síndrome agudo y reversible surgido a resultas de la gripe. Igualmente, la encefalitis letárgica fue otra complicación neurológica vinculada a la enfermedad.

\section{Contacto con el sistema de salud y asistencia sanitaria}

La asistencia sanitaria brindada durante la pandemia se llevaba a cabo tanto a nivel domiciliario como hospitalario en los casos más graves, bien fuese en hospitales civiles o militares. A nivel de recursos humanos, en ocasiones, el personal sanitario era insuficiente, teniendo que tomar el relevo personal religiosos o jóvenes que se formaban como enfermeras a través de la Iglesia católica, como ocurrió en Alemania.

En 1918, si un médico diagnosticaba una EDO (Enfermedad de Declaración Obligatoria), debía comunicarla a las autoridades sanitarias 
pertinentes y de no hacerlo, eran sancionados. Eran así catalogadas las que conllevaban un grave riesgo para la salud pública, entre las cuales no estaba incluida la gripe. Tampoco existía un sistema de alerta en relación con la fecha de comienzo, punto de entrada y velocidad de propagación de la enfermedad. No obstante, desde antaño se sabe que, sensu stricto, son tres las estrategias para contener las enfermedades infecciosas, a saber, cordón sanitario, cuarentena (término acuñado en el siglo XV por los venecianos al mantener fondeados durante cuarenta días a los barcos provenientes de Levante antes de tolerar el desembarco de los tripulantes) y aislamiento ${ }^{13}$.

A lo largo del transcurso de la pandemia, fueron puestas en marcha tres medidas cuyo fin último estribaba en la contención de la enfermedad gripal:

- Identificar los casos prematuramente para así, poder concretar en qué dirección se desplaza la infección.

- Comprender el mecanismo de transmisión y, por consiguiente, tomar las medidas oportunas.

- Disponer de herramientas garantes del cumplimiento de las medidas mencionadas en el apartado previo.

En España los periódicos tomaron la iniciativa de informar lo más ampliamente posible al objeto de disipar las dudas de la población. Al mismo tiempo, publicaron instrucciones de la comisión provincial de sanidad para minimizar el contagio, fundamentadas principalmente en eludir espacios concurridos. En ellos, además, se llegó a acusar a las autoridades políticas de mermar la gravedad del contratiempo y no poner en marcha medidas dirigidas a proteger a la población.

A resulta de los arduos periodos de tiempo derivados de pandemias y guerras, en 1919 se crearon fundaciones de ayuda humanitaria como
Save the Children y, a principios de los años 20, una organización sanitaria precursora de la OMS actual. También es de esta época la creación o restructuración de los ministerios de sanidad en muchos países, así como la inauguración en Viena de una oficina internacional con la misión expresa de combatir las epidemias. Sin embargo, el verdadero hito de esta época es el impulso de la medicina socializada, la cual garantiza una asistencia sanitaria gratuita para todos ${ }^{14}$.

\section{Tratamiento}

No existía disponibilidad de vacunas, fármacos antivirales ni antibióticos para afrontar las infecciones oportunistas cuando se desencadenó la pandemia. Es, por tanto, una época en la que coexisten remedios naturales, compuestos homeopáticos, chamanismo y búsqueda de innovadores tratamientos. En este sentido, se recurrió a la aspirina, la cual era administrada con una posología que la mayor parte de las veces doblaba la dosis segura recomendada hoy en día, debido a sus efectos milagrosos consistentes en atenuar la fiebre y mitigar las algias. Tal es así, que, en el año 2009, la doctora Karen Starko formuló una controvertida teoría cuyo postulado afirmaba que muchas muertes atribuidas a la gripe pudieron deberse a intoxicación por aspirina. Otro de los tratamientos puestos en práctica fue la quinina, hasta entonces usada para combatir la malaria y otras fiebres biliosas de naturaleza palúdica. También, fueron administrados preparados de arsénico, a los que se atribuían cualidades tónicas y analgésicas. Igualmente, el aceite de alcánfor se utilizó para abordar las dificultades respiratorias; la dedalera y estricnina, como estimulantes de la circulación; el sulfato de magnesio y aceite de ricino, como laxantes; y el yodo para la "desinfección interna". Asimismo, suministraron mercurio al objeto de que sus propiedades antisépticas y estimulantes de las glándulas salivares surtieran efecto. No obstante, no tardaron en darse cuenta de que 


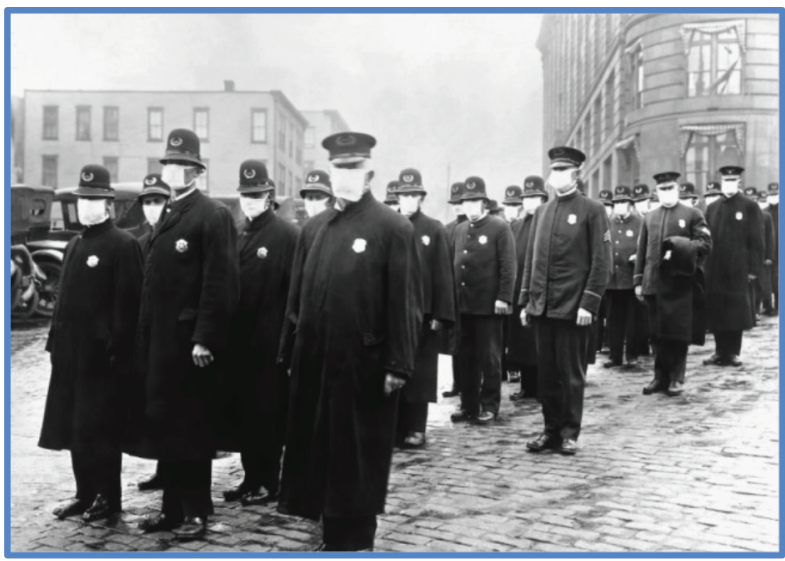

Figura 5. Grupo de policías de Seattle, Estados Unidos, hacia finales de 1918. El uso de mascarilla se hizo habitual durante la pandemia de gripe española. Dominio público, disponible en:

https://commons.wikimedia.org/wiki/File:165-WW-269B-25-police-I_restored.jpg

la pérdida de coordinación y la sensación de hormigueo bajo la piel eran consecuencia de la intoxicación por este metal.

Ya sea por razones bioquímicas o por actuar como nocebos, algunos tratamientos tanto innovadores como tradicionales, agravaron los síntomas.

La arcaica técnica de la sangría medicinal fue recuperada por algunos facultativos al observar que algunos pacientes mejoraban tras sufrir una hemorragia, ya fuera nasal, menstrual o derivada de un aborto.

En este clima de incertidumbre, la única clarividencia con relación a aumentar la supervivencia pasaba por dos prácticas médicas: asegurar que el paciente no se deshidratara y garantizar que recibiera una buena atención.

De aquella época también nos llegan imágenes que ilustran que el uso de mascarillas, como en el momento actual, se convirtió en una medida de salud pública.

\section{Repercusión social}

Son numerosos los aspectos sociales derivados de la pandemia de gripe del siglo XX. Entre ellos podemos reseñar como más significativos la remodelación radical de las poblaciones humanas, el impulso de la sanidad universal, la influencia en el desarrollo de las Guerras Mundiales y la escasez de mano de obra que agravó las restricciones alimentarias como consecuencia de su influencia en las cosechas. También debemos hacer alusión a la estigmatización aún mayor de colectivos ya de por sí marginados, la extinción de determinadas culturas (principalmente de grupos indígenas) y la pérdida de la identidad de grupo una vez resuelto el problema, tal como postula la teoría de la "resiliencia colectiva". Un efecto reactivo fue la promoción de la capacidad biológica de reproducción, el cual es el detonante del auge experimentado por la natalidad a nivel mundial. Además, se promovió la legalización de la adopción de menores consecuente al incremento notable del número de huérfanos, y también se fomentó la formación de los futuros médicos en el ámbito sociológico.

Influencia de la gripe en el arte y las letras “¿Qué es el arte? El arte nace de la alegría y el 
dolor, sobre todo del dolor. Crece a partir de las vidas humanas" - Edvard Munch

Es a partir de los años 20 cuando se produce una vehemente ruptura en el arte. El anhelo de poner fin a los vínculos con la exuberancia del romanticismo $\mathrm{y}$, a fin de cuentas, con el legado del siglo XIX, se ha visto reflejado en todas las artes, desde la literatura a la pintura pasando por la música y el cine. La ciencia y el progreso se quedaron relegados a un segundo plano en el mundo artístico. Con asiduidad se atribuye esta nueva visión derrotista de los artistas a los dos grandes hechos, que como se mencionó con anterioridad, habían causado millones de muertes en el mundo: la gripe española, frente a la cual los avances de la ciencia no habían sido demasiado fructíferos, y la Gran Guerra. A pesar de ello, es frecuente criticar a los intelectuales de aquella época por la exigua influencia que la pandemia de 1918 tuvo en las artes y las letras ${ }^{15}$.

Antes del siglo XX, las enfermedades graves eran bastante frecuentes. En el ámbito literario, cualquier escritor adulto conocido se habría visto ya en 1918 afectado por ellas de uno u otro modo. Además, en ellos había influido el romanticismo decimonónico, que trataba la enfermedad de manera simbólica, como una metáfora del enfermar del alma, carente de interés per se. En este sentido, La montaña mágica de Thomas Mann, escrita en 1912 pero no publicada hasta 1924, era el ejemplo más fehaciente de lo anteriormente expuesto.

En 1918 el historiador y escritor estadounidense A.W. Crosby, en su obra Epidemic and peace (1918) deja constancia de la desoladora situación que, durante la segunda oleada de gripe, vivieron algunas de las más importantes ciudades ${ }^{16}$. También ese mismo año, Eliot hace una posible alusión a la gripe española en el poema Sweeney entre los ruiseñores.

Especial relevancia se le confiere a la escritora británica Virginia Woolf, quien, aquejada de una invalidez permanente, será la primera en cuestionarse por qué la enfermedad no ha sido un tema fundamental de la literatura, y lo hace a través de su ensayo De la enfermedad (1925). Además, ella y James Joyce, serán los grandes renovadores de la novela, los encargados de abrir un nuevo horizonte a la "literatura de la enfermedad" mediante las obras que llevan por título La señora Dalloway (1925) y Ulises (1922), respectivamente ${ }^{15}$.

Otras obras que hacen mención a la gripe española son La tierra baldía (1922), cuyo autor es el anteriormente mencionado Eliot, y El amante de lady Chatterley (1928) de D. H. Lawrence, al cual la enfermedad dejó el corazón y los pulmones debilitados. Esta misma afección la padecería uno de los protagonistas de su obra. También la gripe destruyó los sueños y esperanzas de Miranda, protagonista de Pálido caballo, pálido jinete (1939). Esta obra es el alter ego de la escritora norteamericana K. A. Porter, la cual sufrió los estragos de la pandemia gripal en su juventud, dejando vestigios para el resto de su vida.

Más recientemente, el célebre Miguel Delibes en Mi idolatrado hijo Sisí (1953) recrea la situación experimentada en una capital de provincias con la llegada de la gripe. A su vez, Josep Pla en su Cuaderno gris (1966), sabe dotar de universalidad a lo local a la par que dedicó extensos comentarios acerca de la gripe española ${ }^{16}$. Por último, Pablo Caralps, ya a inicios del presente siglo, escribe el thriller científico Gripe mortal (2009), en el que a través del "robo" de una cepa de gripe española, nos traslada material real bien documentado ${ }^{17}$.

Existen dos autores en los cuales influyó de manera indirecta la gripe. Ellos son Arthur Conan Doyle y Sigmund Freud. El primero, creador del conocido detective "Sherlock Holmes", dejó de escribir ficción tras perder a su hijo a causa de la pandemia. Asimismo, Freud, autor del ensayo que lleva por título Más allá del principio de placer (1920) en el que introduce el concepto de "pulsión de muerte" junto al de "pulsión sexual", 


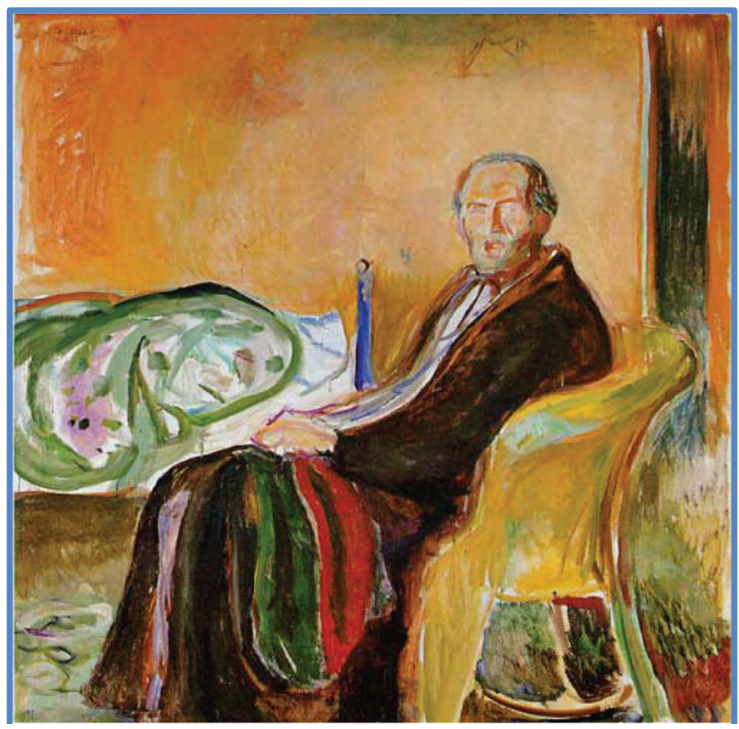

Figura 6. Autorretrato después de la gripe española (E. Munch). Galería Nacional de Noruega. Extraído de Fundación io. Disponible en: http://www.fundacionio.org/img/art/infectio90.jpg

terminó por aceptar que influyó en él la muerte de su hija Sophie en estado de gestación a causa de la gripe ${ }^{15}$.

Conviene reseñar que, en lugares tan dispares como Brasil, China e India, diversos escritores abordaron la enfermedad en sus obras.

De otro modo, en el mundo de la pintura es inevitable reseñar al afamado artista Edvard Munch que, tras sobrevivir a la enfermedad, dejó constancia de las secuelas de ésta en su obra Autorretratos después de la gripe española (1919). En él puede observarse al actualmente, considerado por muchos, padre del expresionismo. Éste se halla inmerso en la soledad, convaleciente, sentado en una silla al lado de la cama y, "mirando sin mirar" al espectador. Con relación a tal postura descrita, se intuye que puede padecer síndrome de fatiga postviral.

Para ultimar, cabe señalar que dos grandes genios de la pintura como Egon Schiele y Gustav Klimt fallecieron por consecuencias derivadas de la gripe. El primero, fundador del expresionismo austriaco, comenzó a pintar La familia, que representaba en realidad a su familia, cuando la enfermedad acechó a la misma. Primeramente, falleció su esposa embarazada y solo tres días después, murió el propio artista a los 28 años. La pintura, aunque no lo parece, nunca ha llegado a concluirse y así ha pasado a la historia, como la obra póstuma de un genio víctima de la crueldad de la gripe. En el caso de Klimt, las complicaciones derivadas de la enfermedad gripal, le llevaron a la tumba después de haber sufrido una reciente hemiplejia que le mantenía postrado. Su discípulo Schiele realizó un dibujo póstumo de Klimt en la morgue de Viena ${ }^{18}$. Engrosarían además la lista de célebres personajes que fallecieron como consecuencia de la gripe el arquitecto Otto Wagner, ideólogo de la mayor parte de los edificios modernistas de la Viena Imperial y de obras civiles como las estaciones de metro vienesas. También el dramaturgo Edmond Rostrand, célebre por dar vida a Cyrano de Bergerac, y el pintor cubista y modernista portugués 
Amadeo De Souza Cardoso. Por último, resaltar que el insigne escritor Guillaume Apollinaire, pilar literario del cubismo y surrealismo, también falleció víctima de la enfermedad. Cuando el escritor Blaise Cendrars lo visitó, comentó que estaba completamente negro y la muerte lo sorprendería al día siguiente ${ }^{15}$.

Para concluir, citar a Franz Kafka y John Dos Passos como supervivientes de la devastadora enfermedad.

Cuatro ilustres artistas, Edvard Munch y Gustav Klimt junto con Egon Schiele y Guillaume Apollinaire, compartieron el hecho de dejar su impronta en la historia del arte y haber fallecido víctimas de la enfermedad más asoladora del siglo pasado.

\section{DISCUSIÓN}

Ardua es la tarea de resignarse, más aún en mayor medida, tras reflexionar acerca de un mundo globalizado, que, jactándose de ser pionero en ciencia y progreso, está padeciendo en el momento actual las funestas y devastadoras repercusiones de una pandemia similar a la acaecida hace un siglo. En aquel entonces la gripe española era la responsable. Hoy lo es el coronavirus SARS-CoV-2, causante de la COVID-19. Parece que cien años ha sido un periodo de tiempo efímero para poner en marcha las herramientas necesarias al objeto de contener de manera eficaz una nueva amenaza impuesta por la naturaleza. Esperemos que, de una vez por todas, la pérdida de múltiples vidas humanas lleve implícita la creación de una conciencia colectiva y de un nuevo paradigma social. También, en palabras de J. R. Calvo, una forma de ver la vida, de relacionarse con otros seres humanos, de cambiar nuestra visión cortoplacista y puramente consumista, por otra que priorice otros valores $^{5}$.

Actualmente debemos concienciarnos de que, además de las pandemias, el cambio climático supone una amenaza más para nuestras vidas, la cual se está dejando relegada a un segundo plano. Si algo positivo nos legó la Plaga de Justiniano, acontecida en el siglo VI, fue que, tras fallecer tantas personas, no había mano de obra que cultivase las tierras. Los bosques dominaron de nuevo con el consiguiente enfriamiento de la Tierra debido a la absorción de $\mathrm{CO}_{2}$ de la atmósfera.

Otro aspecto a considerar es el papel de los medios de transporte y comunicación. Ambos son de suma trascendencia, tanto en la difusión de la enfermedad como en el manejo de la información, respectivamente. A través de los últimos se puede incrementar o decrecer la alarma social en función del momento de la pandemia y, también según la conveniencia de las autoridades en la materia. En la actual pandemia, hemos visto cómo se pasó de enviar mensajes tranquilizadores a la población a concienciar sobre la gravedad del acontecimiento. De otro modo, según manifestaciones de Manuel Carballo en el libro que lleva por título La COVID-19 y sus cadenas de errores, "La gripe de 1918, el SARS y la COVID-19 comparten una característica común y aterradora, a saber, que los seres humanos los transportan de manera fácil e inconsciente cuando se mueven. Esto, mas el hecho de que la enfermedad puede transmitirse por portadores asintomáticos en un mundo de globalización y transporte rápido, significa que, [...] la COVID-19 probablemente habrá tocado tierra en todos los países del mundo"s.

Respecto a la ciencia, hemos de admitir que, si bien ha respondido en cuanto al acúmulo de conocimiento sobre el virus, sus mecanismos de transmisión y su patogenia, no es menos cierto que aún no ha generado nuevos abordajes terapéuticos y la disponibilidad de una vacuna carente de efectos secundarios relevantes es aun incierta. Esto ha condicionado que las medidas de contención para controlar la pandemia sean exactamente iguales en el siglo XX y en el siglo XXI: cuarentena, aislamiento social, seguimiento de 
contactos, cierre de escuelas y universidades, etc. $\mathrm{Ni}$ que decir tiene que esto conlleva grandes pérdidas económicas motivadas por el retraso de la productividad que pueden abocar en último lugar a una recesión a nivel mundial. También cabe señalar que, en continentes como el europeo, con una población sumamente envejecida, apenas se ha invertido en programas de prevención. Igualmente, a pesar de estar dotados de imponentes industrias, "los héroes de la primera línea de fuego" no siempre tenían a su alcance los equipos oportunos e indispensables para hacer frente a la amedrentadora situación. A pesar de los grandes avances en la industria farmacéutica, uno de los principios activos empleado en la gripe de 1918, la quinina, también se utilizó en la actualidad.

Cuando aflora una pandemia, la mayor parte de los esfuerzos se centran en conseguir una vacuna que confiera inmunidad frente al patógeno. Se genera así una competencia ingente que la mayoría de las veces resulta ser motivo de polémica entre investigadores, compañías farmacéuticas, países y la propia población.

Si bien es cierto que el virus no respeta jerarquías $^{9}$, no es difícil que, de forma absolutamente injusta e indigna, surjan como consecuencia de las pandemias ciertas actitudes xenófobas o se estigmatice a determinados colectivos. Ejemplos de ambos casos los encontramos en siglo XX con la población inmigrante italiana en EE. UU. o con pacientes que padecían trastornos psiquiátricos como secuela post-gripal. En pleno siglo XXI, quizás podamos encontrar cierto paralelismo cuando el virus invada países pobres y desfavorecidos en los que van a resultar ridículas medidas higiénicas como el lavado de manos al no existir siquiera agua corriente, o el distanciamiento social en barrios marginales y superpoblados.

En lo que respecta a la población, con frecuencia, surgen determinados grupos que no respetan las indicaciones de las autoridades sanitarias, participando en congregaciones o actos multitudinarios y, además, sin protección alguna en determinados casos. Podemos ejemplificar esto último mediante los actos religiosos llevados a cabo en la ciudad de Zamora o las verbenas de San Isidro celebradas en Madrid durante la pandemia de $1918^{9}$, pero también mediante las huelgas "anti mascarillas" de hoy en día.

Los efectos devastadores de las pandemias ocasionan que muchos niños se queden huérfanos. En la de la gripe española, había que adicionar, además, los huérfanos resultantes del fallecimiento de sus progenitores en los campos de batalla. Solía tratarse de niños de escasa edad cuyos ascendientes, los cuales representaban los pilares o sustentos de las familias, eran relativamente jóvenes también. No debemos olvidar que el pico de fallecimientos se alcanzaba alrededor de la edad de 28 años. Tal es así, que en los inicios de siglo pasado era una práctica común apartar a los huérfanos de sus comunidades y recluirlos en instituciones centralizadas. Con esto, a priori, se intentaba favorecer su integración en una comunidad más amplia y heterogénea, para así abrir sus horizontes al futuro. Nadie pensó que esto podría acarrear consecuencias negativas tales como una pérdida cultural prolongada en el tiempo y en la mayor parte de los casos, irreversible. Además, también se veían obligados a competir por los recursos naturales y el trabajo en las industrias locales. Esto condujo a que se mermase la condición social y psicológica de los nativos de manera inversamente proporcional al incremento de las ayudas gubernamentales. Tal como figura en un ensayo de Napoleón: “[...] Los ancianos aconsejan a los jóvenes nallunguarluku, fingir que no sucedió. Tuvieron que fingir que no sabían muchas cosas. Al fin y al cabo, no solo se trataba de que hubieran muerto sus seres queridos, sino también de que habían visto derrumbarse su mundo". Quizás la única connotación positiva que se puede extrapolar de lo anteriormente expuesto sea que contribuyera a fomentar la legalización de la adopción de menores en Francia en 1923 y en Gran Bretaña, tres 


\section{LA GRIPE ESPAÑ OLA DE 1918 A TRAVÉS DE LA OBRA DE LAURA SPINNEY EL JINETE PÁLIDO \\ MARÍA SAMPEDRO PUERMA; GUILLERMO SÁNCHEZ CAMPELO}

años más tarde, después de muchos intentos infructuosos.

¿Qué aprenderemos de la gripe española y de la pandemia por COVID-19? Ojalá aprendamos que los sistemas públicos deben estar por delante de los privilegios privados y que sin compromiso ciudadano no es posible abordar retos sanitarios de envergadura, ni posiblemente, sostener los pilares de las sociedades democráticas que tanto esfuerzo y vidas ha costado.

A modo de conclusión, podemos decir que la gripe española nos enseñó que las pandemias son inevitables, pero que se cobren más o menos vidas humanas, dependerá del mundo en el que surjan. Quizás, dentro de 100 años, en el bicentenario de la pandemia de 1918, la ciencia pueda dar respuesta a todos y cada uno de los interrogantes que aún siguen planteándose en nuestros días.

\section{Agradecimientos}

Al Profesor Agustín Hidalgo Balsera, por sus orientaciones para la realización del artículo y, especialmente, por haber acrecentado nuestro interés por aquellos aspectos más humanísticos de la medicina.

\section{REFERENCIAS}

1. Breve historia de las pandemias globales: cómo hemos luchado contra los mayores asesinos Infosalus [Internet] 22 de marzo de 2020. [Consultado el 6 de agosto de 2020].

2. Tucidides. Guerra del Peloponeso II. Madrid: Gredos; 1982. p. 359-73.

3. Hugert G. Grandes pandemias de la historia. National Geographic Historia. 22 de junio de 2018.

4. Alinovi M. Historia de las epidemias. Pestes y enfermedades que aterrorizaron (y aterrorizan) al mundo. Madrid: Capital Intelectual; 2009.
5. Carballo M. La COVID-19 y sus cadenas de errores. En Calvo JR, Kindelán C, Calvo Ma A (Eds.). La gran pausa. gramática de una pandemia. Barcelona: Malpaso; 2020. p.19-24.

6. Perdiguero Gil E, Vidal Hernández JM. Las vacunas: historia y actualidad. Menorca: Institut Menorquí d'Estudis; 2008.

7. Fernández Braña M, La lucha continua: Una historia de infecciones y cáncer. Madrid: Editorial Tébar Flores; 2014.

8. Pérez Oliva M. Las malas enseñanzas de las crisis anteriores. El País [Internet], 29 de marzo de 2020. [Consultado el 30 de abril de 2020].

9. Mediavilla D. 1918, la gran epidemia que nadie se tomó en serio. El País [Internet], 22 de marzo de 2020.

10. Spinney L. El jinete pálido. 1918: la epidemia que cambió el mundo. Barcelona: Crítica; 2018.

11. López Sánchez G. Laura Spinney: «La pandemia es una advertencia sobre los peligros reales que afronta la humanidad». (n.d.). ABC [Internet], 30 de abril de 2020. [Consultado el 30 de abril de 2020].

12. Sampedro J. El fantasma de la "gripe española". El País [Internet], 28 de abril de 2009.

13. Pérez Moreda V, Reher DS, Sanz Gimeno A. La conquista de la salud: Mortalidad y modernización en la España contemporánea. Madrid: Marcial Pons; 2015.

14. Ortega F, Lamata F. La década de la reforma sanitaria. Madrid: Exlibris; 1998.

15. Seoane A. Estampas de la gripe, la cultura diezmada. El Cultural [Internet], 6 de abril de 2018.

16. González Núñez J. La verdadera historia de la Gripe del 18. Hoyesarte [Internet]. 18 de marzo de 2020. [Consultado el 18 de marzo de 2020].

17. Otero S. Epidemias narradas, un repaso por algunas obras de la literatura. El Correo Gallego [Internet], 8 de marzo de 2020.

18. González M. ¿Qué nos enseña el arte de pandemias pasadas? El Ágora [Internet], 30 de abril de 2020. 


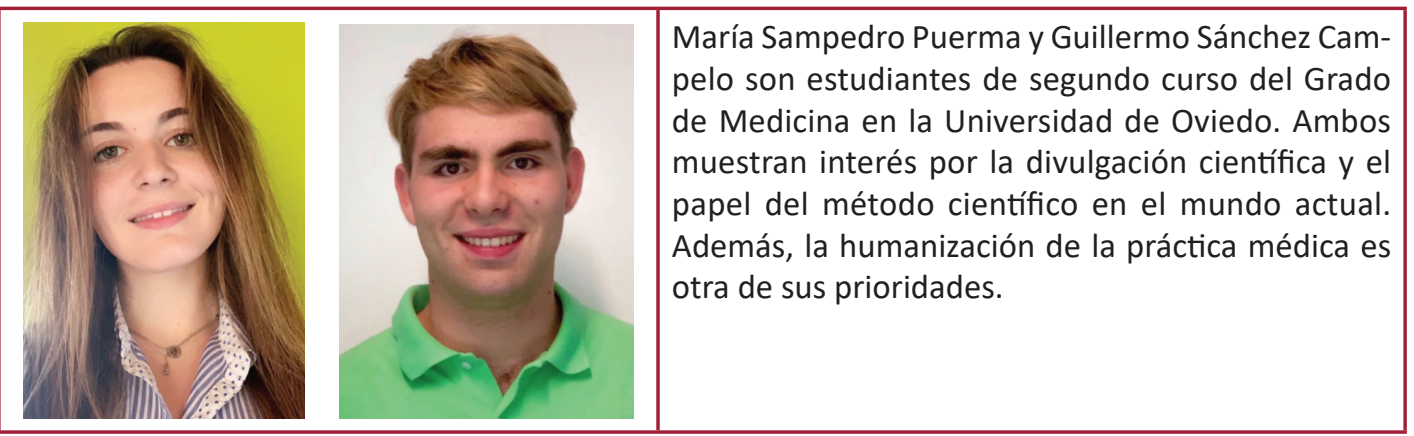

